\title{
Serial Measurement of Regional Cerebral Blood Flow in Patients with Middle Cerebral Artery Stem Occlusion -Report of Two Cases-
}

\author{
Hirotaka SugIYAMA, Haruyuki KanAYA, Michihiro KiRIKAE \\ and Haruhiko HASEGAWA
}

Department of Neurosurgery, Iwate Medical University, Morioka

\begin{abstract}
Regional cerebral blood flow (rCBF) in two patients with middle cerebral artery stem occlusion (one characterized by persistent occlusion and the other by spontaneous recanalization) was measured repeatedly by dynamic single-photon emission computed tomography and ${ }^{133} \mathrm{Xe}$ gas steady-state inhalation. With the exception of complete recanalization in one patient, the pathophysiology in the two cases appeared essentially the same. These cases are described and the problems of measuring and interpreting rCBF in cerebral infarction are addressed. The concept of a "homeostatic mechanism of cerebral energy supply" is also discussed.
\end{abstract}

Key words: regional cerebral blood flow, cerebral infarction, luxury perfusion, misery perfusion, matched perfusion, computed tomography

\section{Introduction}

In two representative patients with middle cerebral artery (MCA) stem occlusion (one with persistent occlusion and the other with spontaneous recanalization), the final tomographic images of regional cerebral blood flow (rCBF) were surprisingly similar, despite the markedly peculiar rCBF dynamics ("luxury perfusion") in the patient with recanalization.

The data from these serial observations strongly support the hypothesis that there is a homeostatic mechanism with respect to the cerebral energy supply and imply that $\mathrm{rCBF}$ is regulated by this mechanism according to the brain metabolic requirement. This principle has been well documented in positron emission tomographic (PET) studies..$^{2.3,8,17.22 .44)}$ The rCBF dynamics of our two cases are discussed with special reference to this hypothesis.

\section{Patients}

Case 1: A 58-year-old male with no previous neurological disorder was hospitalized with sudden,

Received October 13, 1986; Accepted August 19, 1987 complete right hemiplegia and total aphasia without impairment of consciousness. He recovered from this episode and was able to walk with a cane within 2 months of its onset, although paralysis of right upper extremity, and severe motor and moderate sensory aphasia remained.

A computed tomographic (CT) scan obtained on the day after onset showed a large low-density area in the left MCA-perfused region (Fig. 1). Angiography on the 3rd day after onset revealed complete occlusion of the left MCA stem just beyond the divergence of a few medial branches of the lenticulostriate arteries (Fig. 2). Persistent occlusion was demonstrated by digital subtraction angiography on the 44th day, but details of the perforating arteries were unclear because of poor resolution.

Case 2: A 60-year-old male with a history of myocardial infarction was hospitalized with sudden onset of moderate right hemiparesis and total aphasia without impaired consciousness. The hemiparesis had almost completely disappeared within 2 weeks after onset, but severe motor and slight sensory aphasia remained.

A CT scan on the 9th day after onset disclosed a large low-density area in the left MCA-perfused territory (Fig. 3). Angiography 2 days after onset dem- 

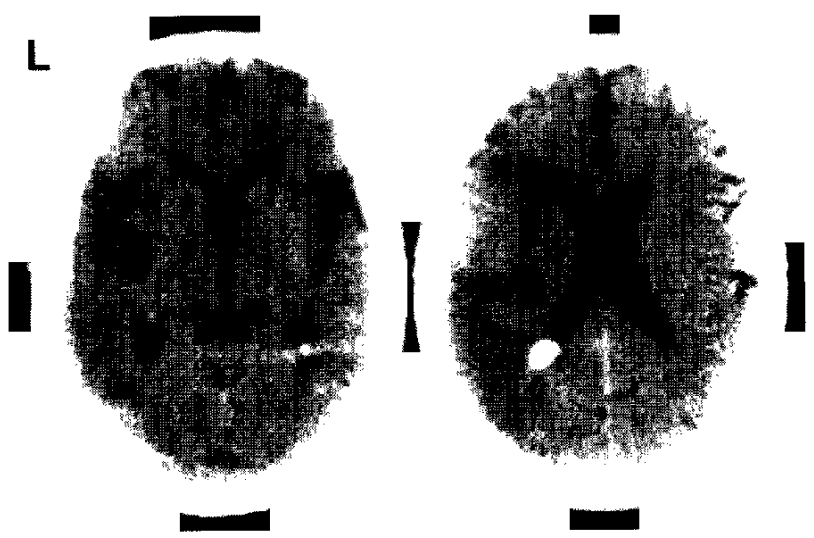

Fig. 1 Precontrast CT scan in Case 1 (persistent occlusion of the left MCA stem), obtained on the day after onset.

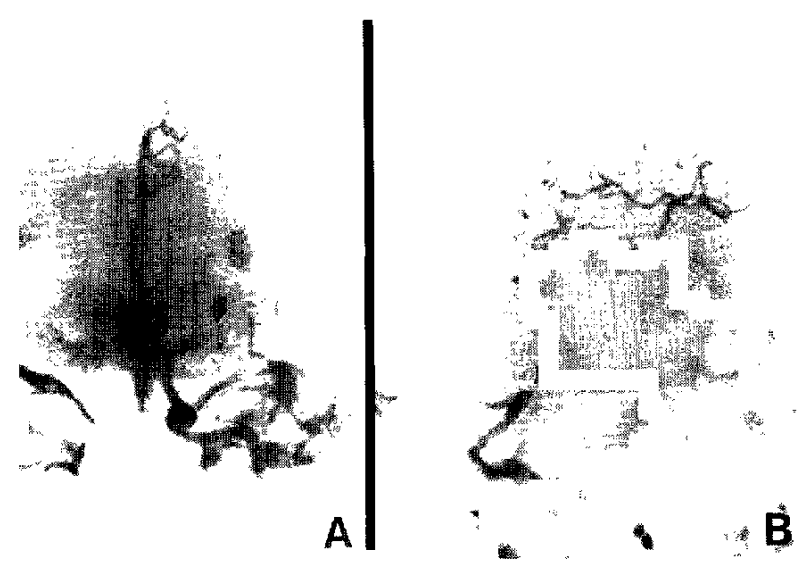

Fig. 2 Case 1. Angiograms obtained on the 3rd day show complete occlusion of the left MCA stem (arrow). A: anteroposterior view, B: lateral view.

onstrated neither occlusion nor stenosis of the left MCA, but showed a small arterial plaque, which stenosed the left internal carotid artery (ICA) by $25 \%$ (Fig. 4). This finding suggested transient embolic occlusion of the MCA stem and subsequent recanalization.

Both patients were treated conservatively, without fibrinolytic or hemodilution therapy.

\section{Methods}

The rCBF was measured at $5 \mathrm{~cm}$ above the orbitomeatal plane by means of dynamic single-photon emission CT (D-SPECT) with 32 rotating detectors containing NaI scintillators (Tomomatic-32, Medimatic Ltd., Denmark).

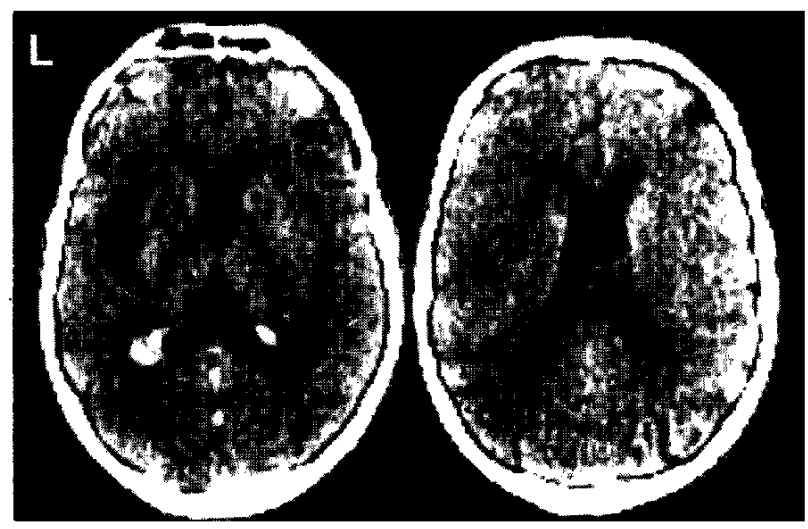

Fig. 3 Precontrast CT scan in Case 2 (left MCA stem occlusion followed by subsequent recanalization), obtained on the 9th day after onset.

${ }^{133} \mathrm{Xe}$ gas was administered by inhalation through a mouthpiece for the initial 1.5 minutes, and exhaled for the next 3 minutes for reconstruction of four consecutive ${ }^{133} \mathrm{Xe}$ distribution maps of the brain. A mixture of oxygen and 60 to $80 \mathrm{mCi}$ of ${ }^{133} \mathrm{Xe}$ gas was prepared in 4-1 rubber bag according to the lung permeability of each patient, so that a stable head count rate of 160 to $240 \times 10^{3}$ counts $/ \mathrm{min} / 32$ detectors was obtained in the second 1 -minute period.

The spatial resolution (FWHM) obtained with this apparatus in an ${ }^{133} \mathrm{Xe}$ phantom study was 20 to 25 $\mathrm{mm}$ axially and transversely, depending on the distance from the detector system. The energy discrimination level was adjusted at $20 \%$ below the photo-

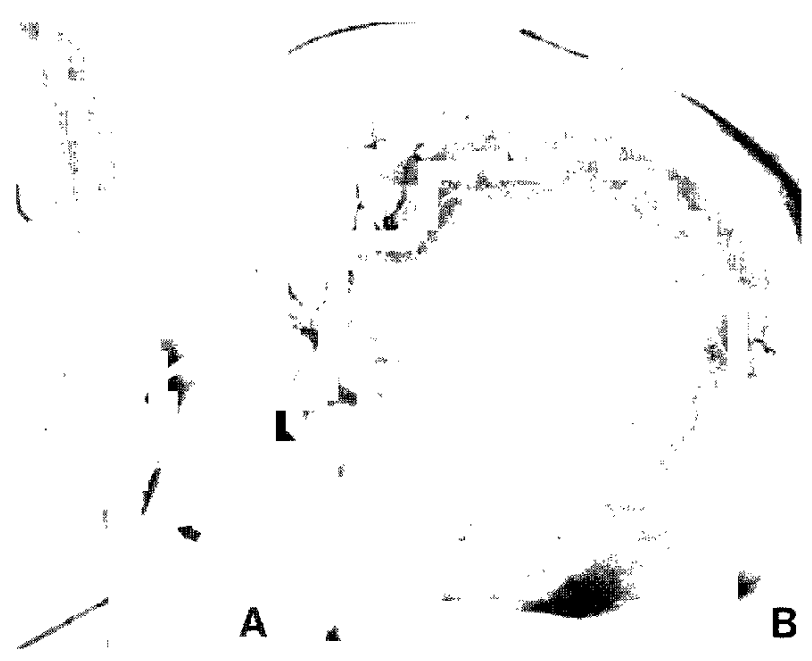

Fig. 4 Case 2. Angiograms obtained on the 2nd day show 25\% stenosis of the left ICA (A, arrow) and the left MCA branches after recanalization $(B$, lateral view).

Neurol Med Chir (Tokyo) 28, January 1988 
peak of $81 \mathrm{keV}$. A brain-blood partition coefficient of $1.0 \mathrm{ml} / \mathrm{gm}$ was employed in all areas of the brain.

The rCBF values were calculated tomographically on the basis of the four consecutive ${ }^{133} \mathrm{Xe}$ distribution maps by the use of two algorithms s,14,37 $^{\text {- }}$ the "early picture" and "sequence of pictures" methods. The limit of application of these two algorithms was 70\% of ${ }^{133} \mathrm{Xe}$ accumulation. The results were displayed on a tomographic rCBF distribution map on 128 matrix with a graded, 16-color scale, and the absolute values were also printed out on a $32 \times 32$ matrix, each pixel corresponding to a brain area of approximately $7 \times 7$ $\mathrm{mm}^{2}$. Thus, each hemisphere comprised 150 to 190 pixels, depending on the head size.

With these measurement techniques, normal hemispheric $\mathrm{CBF}$ was estimated to be $68.5 \pm 9.8$ $\mathrm{ml} / 100 \mathrm{gm} / \mathrm{min}[\mathrm{n}=11$, mean age $=40.4 \pm 11.8$ years, arterial $\mathrm{CO}_{2}$ tension $\left(\mathrm{PaCO}_{2}\right)=42.8 \pm 5.7$ $\mathrm{mmHg}$, mean arterial blood pressure $(\mathrm{MABP})=$ $105 \pm 17 \mathrm{mmHg}$. No significant right-left hemispheric difference $(1.1 \pm 0.8 \%)$ was observed (Fig. 5 A). ${ }^{8,17,22)}$ Reproducibility was demonstrated in a patient with a left temporal arteriovenous malformation by repeating measurement 50 minutes later, when the remaining ${ }^{133} \mathrm{Xe}$ activity had dropped below 7.3\% (Fig. 5B and C).

\section{Results}

Case 1: Resting rCBF was measured on the 2nd, 10th, 13th, 38th, and 52nd days after onset (Fig. 6). MABP and $\mathrm{PaCO}_{2}$ were described in the legends of Fig. 6. The rCBF values calculated from the 80 pixels corresponding to the MCA-perfused cortical regions of both (ipsilateral/contralateral) hemispheres were as follows: $21.2 / 42.5,28.1 / 48.8,39.7 / 64.4,34.8 /$ 65.8 , and $28.5 / 62.0 \mathrm{ml} / 100 \mathrm{gm} / \mathrm{min}$ (Fig. 7).

Less recoverable rCBF reduction in the left (ipsilateral) hemisphere and prominent diaschitic rCBF reduction in the right (contralateral) hemisphere were characteristic of this case of persistent occlusion.

Case 2: Similarly to Case 1 , measurements were obtained on the 8th, 10th, 15th, 22nd, and 43rd days after onset (Fig. 8). The rCBF values were as follows: $119 / 51.5,86.8 / 52.4,54.5 / 57.0,33.9 / 56.9$, and $31.1 /$ $59.5 \mathrm{ml} / 100 \mathrm{gm} / \mathrm{min}$ (Fig. 7).

The black areas in the rCBF tomograms of days 8 and 10 represent high $\mathrm{rCBF}$ values $(>112 \mathrm{ml} / 100$ $\mathrm{gm} / \mathrm{min}$ ), which went beyond the color scale. Timedependently recoverable "luxury perfusion" in the left (ipsilateral) hemisphere was the noteworthy finding in this case of recanalization. On days 8 and 10 , the number of pixels indicating $\mathrm{rCBF}$ values of more than $90 \mathrm{ml} / 100 \mathrm{gm} / \mathrm{min}$ were 67 and 38 , respectively, and their mean values were 137 and $112 \mathrm{ml} /$ $100 \mathrm{gm} / \mathrm{min}$, respectively. The maximum $\mathrm{rCBF}$ value indicated by any pixel was $200 \mathrm{ml} / 100 \mathrm{gm} / \mathrm{min}$ and occurred on day 8 .

\section{Discussion}

\section{Methodological considerations}

Along with the many advantages of combining three-dimensional visualization with a noninvasive procedure, the low energy of ${ }^{133} \mathrm{Xe}$ and its slow passage to the brain give rise to the two unavoidable problems of limited spatial resolution, especially of the deep structures, and unreliability of rCBF calculations for white matter (which are overestimated by a factor of approximately 2.5 ).

Nevertheless, the information this system offers is quite reproducible throughout the brain, provided that the head is precisely positioned, the dose of ${ }^{133} \mathrm{Xe}$ is sufficient, and the patient's tidal exchange is stable. Therefore, not only the right and left hemispheric difference ${ }^{21,22)}$ but also absolute $\mathrm{rCBF}$ values obtained at different times from a given cortical area in the same patient can be compared.

However, great care should be taken, in selecting the homolateral and/or homologous region of interest (ROI) on the print-out, to minimize errors of artificial manipulation. Also, the statistical unreliability of individual pixels must be kept in mind. In general, the larger the ROI, the greater the reliability. ${ }^{22)}$ In fact, a ROI larger than $4 \times 4$ pixels (a tomographic brain area of $28 \times 28 \mathrm{~mm}^{2}$ ) is recommended, taking the spatial resolution of this apparatus ( 20 to $25 \mathrm{~mm}$ of FWHM) into account.

\section{Significance of rCBF dynamics in cerebral in- farction}

Conventional concept: In an attempt to elucidate the pathophysiology of cerebral infarction, many investigations $\left.{ }^{1,11}, 12,15,16,18-21,23,24,26-29,35,42\right)$ have been based on human rCBF dynamics. However, in large part the pathophysiology of cerebral infarction has not been clarified because of the following problems. First, cerebral infarction involves a complicated combination of factors, ${ }^{22)}$ e.g., age, medical history, severity of the primary ischemia, location and extent of the affected brain region, and primary disease of the patient. In particular, the site and severity of the primary ischemia and whether or not it involves the basal ganglia and/or thalamus ${ }^{6,38)}$ seem to strongly influence rCBF dynamics, which renders the interpretation of rCBF data very confusing. The second problem concerns time-dependent changes in rCBF 

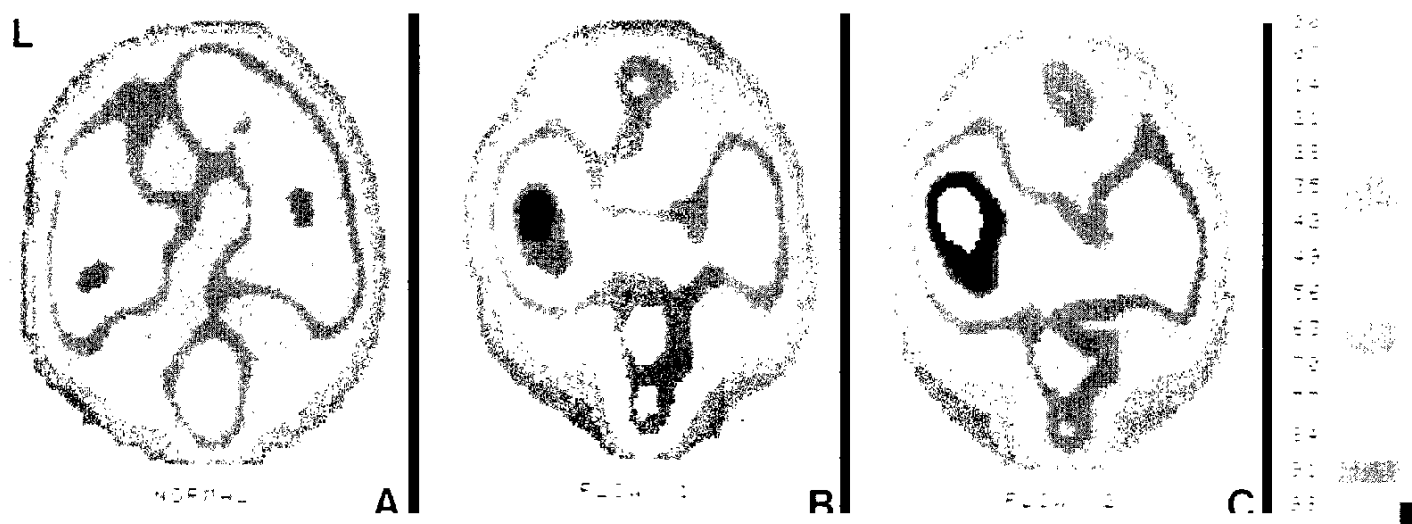

Fig. $5 \mathrm{~A}$ : rCBF tomogram of a normal adult in the resting state (MABP $=110 \mathrm{mmHg}, \mathrm{PaCO}_{2}=45.1$ $\mathrm{mmHg}$ ). B, C: Reproducibility of $\mathrm{rCBF}$ tomography after a 50-minute interval in the same patient with an arteriovenous malformation in the left temporal lobe (B: first measurement; $\mathrm{MABP}=87 \mathrm{mmHg}, \quad \mathrm{PaCO}_{2}=48.4 \mathrm{mmHg} . \quad \mathrm{C}$ : second measurement; $\mathrm{MABP}=88 \mathrm{mmHg}$, $\left.\mathrm{PaCO}_{2}=49.4 \mathrm{mmHg}\right)$. These tomograms are arrayed in a graded, 16 -color scale $(\mathrm{ml} / 100 \mathrm{gm} /$ min).

L
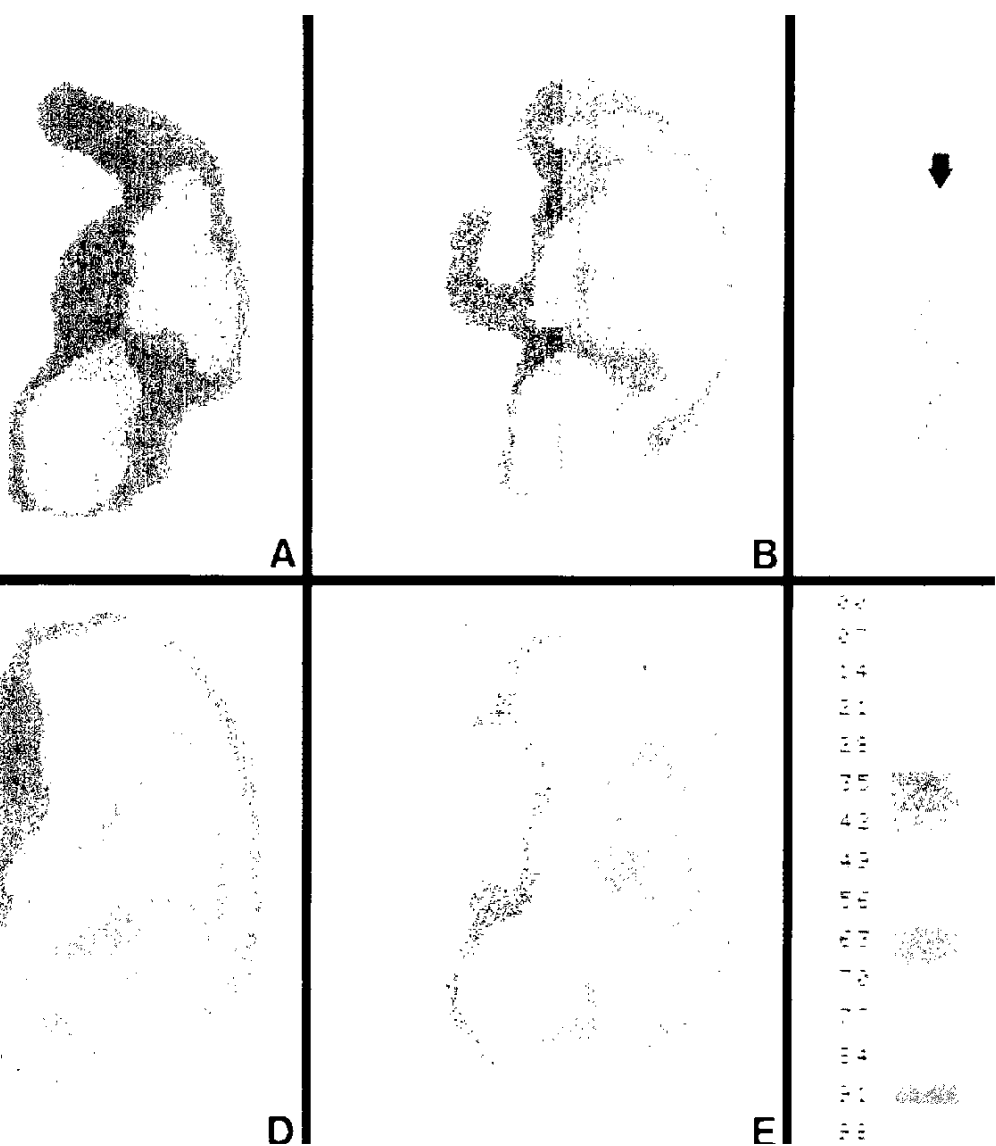

C.

Fig. 6 rCBF tomograms in Case 1 in the resting state at various intervals after onset. A: 2nd day; $\mathrm{MABP}=119 \mathrm{mmHg}, \mathrm{PaCO}_{2}=34.8 \mathrm{mmHg}$. B: 10 th day; $\mathrm{MABP}=110 \mathrm{mmHg}, \mathrm{PaCO}_{2}=37.2$ mmHg. C: 13 th day; $\mathrm{MABP}=100 \mathrm{mmHg}, \mathrm{PaCO}_{2}=38.9 \mathrm{mmHg}$. D: 38th day; $\mathrm{MABP}=103$ $\mathrm{mmHg}, \mathrm{PaCO}_{2}=40.4 \mathrm{mmHg}, \quad \mathrm{E}$ : 52nd day; $\mathrm{MABP}=117 \mathrm{mmHg}, \mathrm{PaCO}_{2}=41.7 \mathrm{mmHg}$. These tomograms are arrayed in a graded, 16 -color scale $(\mathrm{ml} / 100 \mathrm{gm} / \mathrm{min})$. 


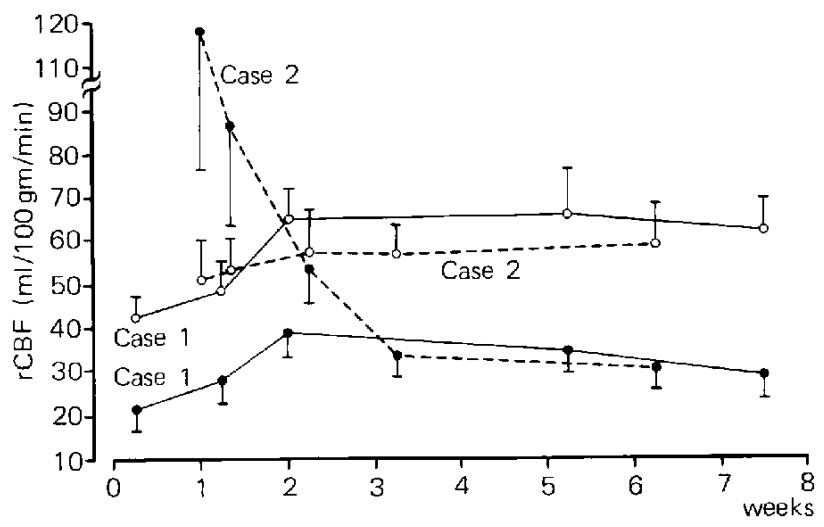

Fig. 7 Sequential changes in $\mathrm{TCBF}$ calculated from the 80 pixels corresponding to the MCA-perfused cortical area in both hemispheres. lateral hemisphere, $O$ : contralateral hemisphere. dynamics after onset, ${ }^{22)}$ a phenomenon that was clearly illustrated in the present study. However, conventional methods of measuring rCBF cannot be repeated frequently because of the invasiveness of intra-arterial injection. The third problem requires reassessment of the relationship between $\mathrm{rCBF}$ and cerebral metabolism: We do not know for sure what rCBF represents. If the presupposition that $\mathrm{rCBF}$ directly reflects cerebral metabolism is not true, $\mathrm{rCBF}$ values may be meaningless.

Regarding the relationship between $\mathrm{rCBF}$ and metabolism, Kety ${ }^{16)}$ first reported that cerebral $\mathrm{O}_{2}$ consumption is confined to a rather narrow range, whereas cerebrovascular resistance tends to fluctuate over a considerable range. Since Kety's report it has been well documented that $\mathrm{rCBF}$ and cerebral metabolism are generally as well as regionally interdependent, in normal brain ${ }^{2,3,8,13,17,22,30,36,44)}$ as well
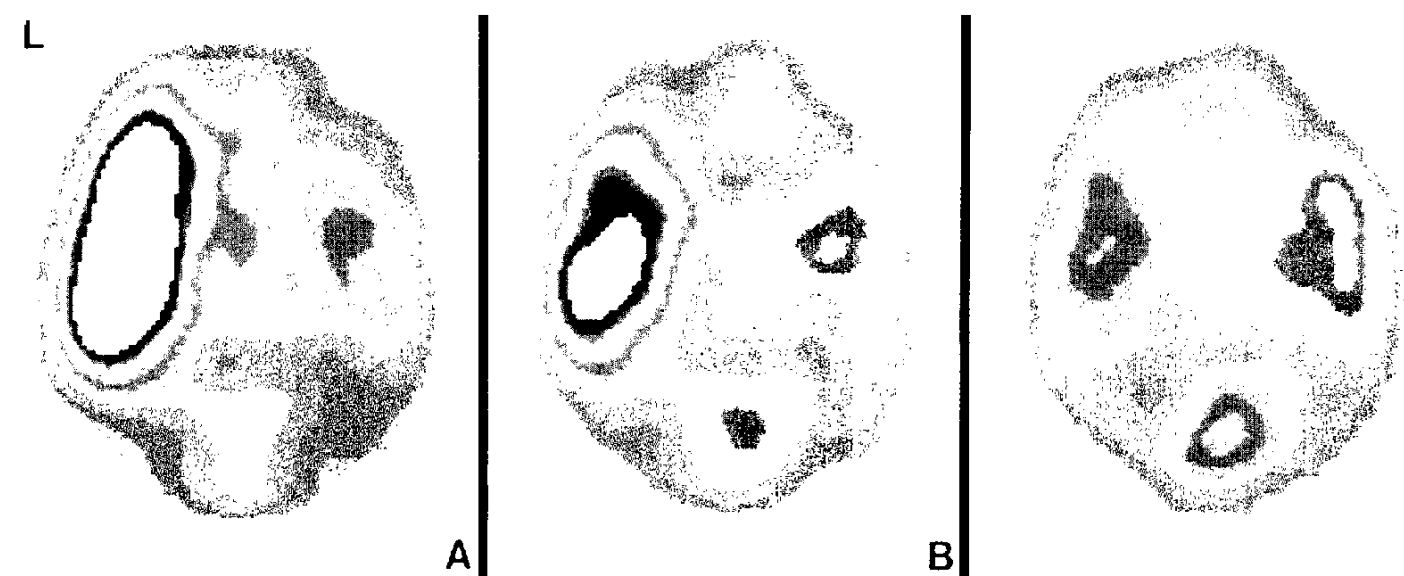

A

B

r.
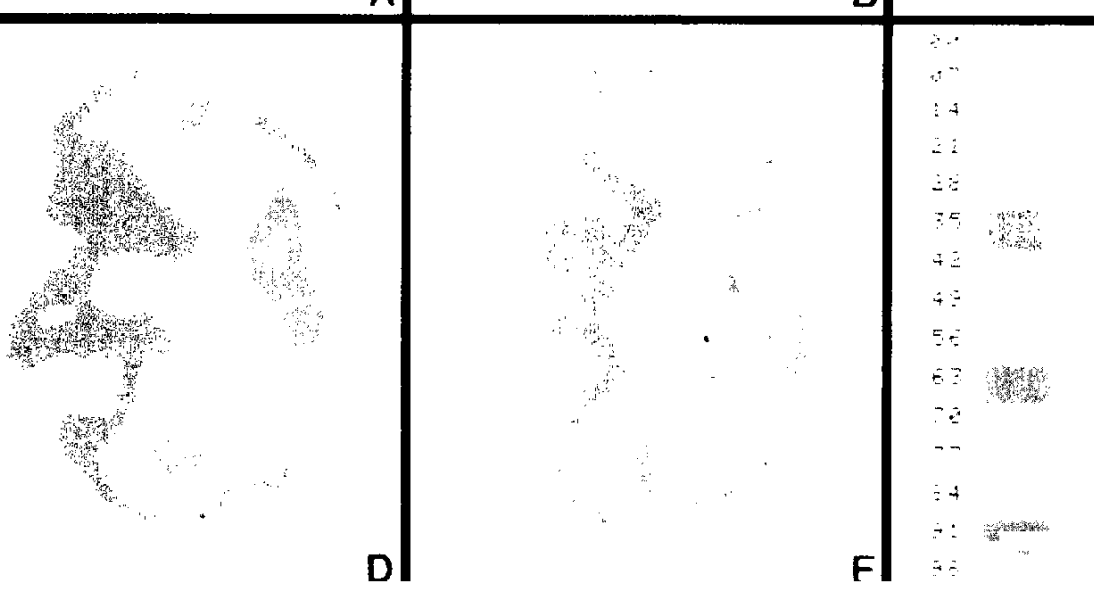

Fig. 8 rCBF tomograms in Case 2 in the resting state at various intervals alter onset. A: 8th day; $\mathrm{MABP}=107 \mathrm{mmHg}, \mathrm{PaCO}_{2}=40.0 \mathrm{mmHg}$. B: 10 h day; $\mathrm{MABP}=99 \mathrm{mmHg}, \mathrm{PaCO}_{2}=39.3$ $\mathrm{mmHg}$. C: 15 th day; $\mathrm{MABP}=90 \mathrm{mmHg}, \mathrm{PaCO}_{2}=42.4 \mathrm{mmHg}$. D: 22nd day; $\mathrm{MABP}=89$ $\mathrm{mmHg}, \mathrm{PaCO}_{2}=41.5 \mathrm{mmHg}$. E: 43rd day; $\mathrm{MABP}=94 \mathrm{mmHg}, \mathrm{PaCO}_{2}=42.6 \mathrm{mmHg}$. These tomograms are arrayed in a graded, 16 -color scale $(\mathrm{ml} / 100 \mathrm{gm} / \mathrm{min})$. 
as in diseased brain at the chronic stage..$^{22,30)}$ In other words, it is safe to assume that each brain has its own "metabolic demand," which fluctuates to some extent in accordance with the status of cerebral function.

Present concept: On the basis of the information we have, it appears reasonable to interpret $\mathrm{rCBF}$ dynamics in cerebral infarction in terms of a relationship between "energy supply" and "metabolic demand."

It is no exaggeration to say that the advent of PET, which measures both rCBF and metabolism, has contributed substantially to the establishment of the new concept of cerebral perfusion, which disregards the actual rCBF values and has given rise to the terminology "matched" situation," "misery perfusion,", ${ }^{2,4)}$ and "Iuxury perfusion.", 18,22)

In light of this concept, comparison of the rCBF dynamics in our two cases, in which the only major pathophysiological difference involved recanalization, offers many interesting suggestions about dynamic pathophysiological changes in cerebral infarction.

\section{Interpretation of the present cases}

Diaschitic contralateral $\mathbf{C B F}$ reduction: In the contralateral hemispheres in both cases, moderate rCBF reduction was observed within 2 weeks after onset, followed by subsequent recovery to the normal range (Fig. 7). Such a transient functional depression, distant from the circumscribed lesion, was initially described by von Monakow, ${ }^{43)}$ who termed it "diaschisis." Høedt-Rasmussen et al. ${ }^{11)}$ described the analogous concept of "transhemispheric depression," which is confined to the contralateral hemisphere and is ascribed to a reduction in cerebral metabolism secondary to disruption of interhemispheric neuronal connections.

Mayer et al. ${ }^{24)}$ Ginsberg et al., ${ }^{97}$ and others using $\mathrm{PET}^{2,3,17,44,45)}$ have recently quantitated decreases in $\mathrm{rCBF}$ and cortical metabolism and proved that, with few exceptions, ${ }^{22,35)}$ the reductions occur in parallel. Sugiyama $^{38)}$ observed diaschitic $\mathrm{rCBF}$ reduction in cases of small intracerebral hematoma without evident mass effect and suggested that destruction of the basal ganglia or thalamus ${ }^{23)}$ plays an extremely important role in the disruption of interhemispheric neuronal connections. These observations strongly support the postulated concept of diaschisis, whereas morphological evidence of concrete neuronal pathways remains insufficient. ${ }^{11,24)}$

However, it should be noted that the concept of diaschisis explains only the "metabolic demand." In order to fully understand not only diaschisis, but also the means of $\mathrm{rCBF}$ regulation under various brain conditions, two additional factors must be addressed. One is "energy supply" (perfusion pressure) as a counterpart of metabolic demand. The other is the postulated concept of a "homeostatic mechanism of cerebral energy supply," which intervenes between "demander" and "supplier" to ensure that the $\mathrm{rCBF}$ is adequate but not excessive through dynamic control of cerebrovascular resistance within a rather wide but definite range (the authors term such rCBF dynamics "matched perfusion").

On this basis, the conventional concept of "autoregulation" can be regarded as a concretization of the homeostasis of the cerebral energy supply. Diaschitic $\mathrm{rCBF}$ reduction, then, can be redefined in terms of a "supplier of energy" and a "homeostatic mechanism" that are intact despite a decreased "metabolic demand." Regarding "recoverability," it might be considered that reversal of the diaschitic rCBF reduction is attributable to restoration of the metabolic demand, but why and how that might occur remains unknown.

Possible explanations include compensatory rearrangement of synaptic configurations via the "sprouting" phenomenon of neurons ${ }^{41)}$ and/or reactivation of "idling" neurons. ${ }^{46)}$

Meanwhile, there is still controversy as to what the working components are that achieve homeostasis of the cerebral energy supply and how they so competently control cerebrovascular resistance. The only references are to myogenic ${ }^{391}$ and chemical factors, ${ }^{16,20,34)}$ vasoactive substances, ${ }^{35)}$ and neurogenic factor. ${ }^{7}$ 10,16,20,32,33) However, in our opinion it is reasonable to assume that this organization comprises several concrete, closely interconnected mechanisms regulated by a feedback system.

rCBF dynamics in the recanalized hemisphere: In the ipsilateral hemisphere in our Case 2, a marked, widespread $\mathrm{rCBF}$ increase that exceeded the metabolic demand was observed (Fig. 8A and B). Such an rCBF dynamics was termed "luxury perfusion" by Lassen, ${ }^{18)}$ and his report was followed by many others ${ }^{12,25,27,40,42)}$ on this phenomenon, in which it was described as rather frequent and transitory in nature. Uemura et al. ${ }^{42)}$ presented a case of $\mathrm{rCBF}$ alteration in a recanalized infarction followed by luxury perfusion, measured on the 7 th and 21 st days after onset by the ${ }^{133} \mathrm{Xe}$ intra-arterial injection method, showing a tendency toward rCBF normalization. However, our study may be the first in which the full course of time-dependent dynamic rCBF changes, followed by spontaneous recanalization, have been documented in one patient. The most noteworthy finding is that the luxury-perfused 
hemisphere finally recovered to its normal perfusion state (matched perfusion). This course closely paralleled the $\mathrm{rCBF}$ reduction pattern that occurred in the patient with MCA stem occlusion about 6 weeks after onset (Figs. 6E and $8 \mathrm{E}$ ).

It seems to be generally accepted that luxury perfusion is caused by interstitial acidosis of surrounding vessels due to delivery of anaerobic metabolites. ${ }^{12,18,27-29,42)}$ However, before discussion of the cause of this phenomenon, it should be mentioned that there are two different types. One is mild and unaccompanied by recanalization at the borderzone surrounding or adjacent to the infarcted region (the "borderzone type") $)^{12,25,27,28,42)}$ and the other is moderate to marked and follows recanalization in the infarcted region ${ }^{12,25,27,42)}$ (the authors term this the "focal type"). Indeed, metabolic acidosis plausibly explains the borderzone type of luxury perfusion, as Ogawa et $a l .{ }^{25}$ confirmed experimentally. It deserves mention that the brain area suffering luxury perfusion of the borderzone type is functionally as well as morphologically intact and only reacts normally under the acidic circumstance caused by the infarcted region. However, there naturally arises the question of how anaerobic glycolysis could continue in the focal type of luxury perfusion for the long interval ${ }^{42)}$ of 3 to 4 weeks, as happened in our Case 2 , in which perfusion was excessive (Fig. 7). A more likely cause of the focal type of luxury perfusion is reversible dysfunction of the homeostatic mechanism of the cerebral energy supply owing to the paralysis of vascular resistance accompanying the primary ischemic event ${ }^{311}$ in the infarcted area. In other words, the focal type of luxury perfusion may merely be an expression of reversible cerebrovascular paralysis manifested under the restored perfusion pressure (supplier of energy). Therefore, the magnitude and duration of this phenomenon must be determined mainly by the severity of damage to cerebral resistance vessels. ${ }^{40)}$ On rare occasions severe, necrotizing ischemia may cause a concomitant hemorrhagic infarction. ${ }^{12,42)}$ Thus, the pathophysiological significance of these two types of luxury perfusion may be considered to differ fundamentally.

On the other hand, another significant question is whether or not excessive reperfusion is actually detrimental to brain tissue ${ }^{18,25)}$ and thereby exacerbates the situation. ${ }^{(2,29,40,42)}$ It is noteworthy in this regard that Case 2 showed no neurological deterioration during the interval of luxury perfusion. Ogawa et al. ${ }^{25)}$ experimentally demonstrated the existence of a brain region between the intact rim and infarcted core that is devitalized following postischemic recirculation. This diversity of results of this problem may well be attributed to the severity and extent of cerebral tissue damage, determined by "primary" ischemia, ${ }^{40)}$ which may change cell-membrane properties ${ }^{18)}$ so as to accelerate "brain edema" such that the affected region will readily succumb to the restored hydrodynamic pressure following reperfusion.

rCBF dynamics in occluded hemisphere: It is difficult to correctly evaluate the pathophysiology of the occluded hemisphere (Case 2) because no dramatic rCBF alteration took place, in contrast with the contralateral diaschitic $\mathrm{rCBF}$ decrease and, in Case 1, the marked ipsilateral $\mathrm{rCBF}$ increase. The most severe $\mathrm{rCBF}$ reduction, which occurred 2 days after onset, is regarded as reflecting an increased oxygen extraction rate (OER), which was described by Wise et al. (misery perfusion). ${ }^{44,45)}$ This compensates for the reduced rCBF supply due to the lowered perfusion pressure (supplier of energy) due to the poor collateral circulation in the "very" acute stage (Fig. 6A). There are two possible reasons why the borderzone type of luxury perfusion was not observed in the acute stage: ${ }^{17,22,27,29,42)}$ the oxygen supply for aerobic glycolysis was adequately compensated for by the increase in the OER, which resulted in no production of anaerobic metabolites or, because of limited resolution, the apparatus failed to detect the existence of mild luxury perfusion of the borderzone type.

The relative rCBF increase on the 13th day (Fig. 6C, arrow) is considered the focal type of luxury perfusion. The partial restoration of local perfusion pressure occurs through either intraembolic revascularization or short distal migration of the embolus without a significant change in the angiogram. In any case, emergence of the focal type of this phenomenon implies that insufficiency of the "homeostatic mechanism of the cerebral energy supply" still existed in the infarcted area at this period.

We conclude that there was no significant difference in the essential pathophysiology in these two cases, with the exception of complete recanalization in one patient.

\section{Conclusion}

Repeated rCBF measurements by D-SPECT can noninvasively demonstrate the time-dependent alterations in $\mathrm{rCBF}$ dynamics in cerebral infarction. The conditions of misery and luxury perfusion are transient phenomena observed in the early period of cerebral infarction, before the brain recovers to a matched-perfusion state in the chronic phase.

Assessment of rCBF dynamics in terms of the 
relationships among metabolic demand, perfusion pressure, and the homeostatic mechanism of the cerebral energy supply may advance our understanding of the pathophysiology of the brain.

\section{Acknowledgment}

The authors wish to express their sincere gratitude to Prof. N.A. Lassen and collaborators, of the Department of Clinical Physiology, Bispebjerg Hospital, Copenhagen, Denmark, for making this study possible.

\section{References}

1) Astrup J, Siesjö BK, Symon L: Thresholds in cerebral ischemia. The ischemic penumbra. Stroke 12: 723-725, 1981

2) Baron JC, Bousser MG, Comar D, Kellershohn C: Human hemispheric infarction studied by positron emission tomography and the ${ }^{15} \mathrm{O}$ continuous inhalation technique, in Caille JM, Salamon G (eds): Computerized Tomography. Berlin, Springer, 1980, pp 231-237

3) Baron JC, Lebrun-Grandie P, Collard P, Crouzel C, Mestelan G, Bousser MG: Noninvasive measurement of blood flow, oxygen consumption, and glucose utilization in the same brain regions in man by positron emission tomography: Concise communication. I Nucl Med 23: 391-399, 1982

4) Baron JC, Rougemont D, Bousser MG, LebrunGrandie P, Iba-Zizen MT, Chiras J: Local CBF, oxygen extraction fraction (OEF), and $\mathrm{CMRO}_{2}$ : Prognostic value in recent supratentorial infarction in humans. J Cereb Blood Flow Metabol 3 [Suppl] 1: 12, 1983

5) Celsis P, Goldman T, Henriksen L, Lassen NA: A method for calculating regional cerebral blood flow from emission computed tomography of inert gas concentrations. J Comput Assist Tomogr 5: 641-645, 1981

6) DeLaPaz RL, Patronas NJ, Brooks RA, Smith BH, Kornblith PL, Milam H, Dichiro G: A PET study of suppression of glucose utilization in cerebral gray matter associated with brain tumor. $J$ Cereb Blood Flow Metabol 3 [Suppl] 1: 21-22, 1983

7) Deshmukh VD, Harper AM, Rowan JO, Jennett WB: Studies on neurogenic control of the cerebral circulation. Eur Neurol 6: 166-174, 1971/72

8) Frackowiak RSJ, Lenzi GL, Jones T, Heather JD: Quantitative measurement of regional cerebral blood flow and oxygen metabolism in man using ${ }^{15} \mathrm{O}$ and positron emission tomography: Theory, procedure, and normal values. $J$ Comput Assist Tomogr 4: 727736,1980

9) Ginsberg $\mathbf{M}$, Reivich M, Giandomenico A, Greenberg $\mathrm{JH}$ : Local glucose utilization in acute focal cerebral ischemia: Local dysmetabolism and diaschisis. Neurology (Minneap) 27: 1042-1048, 1977

10) Hernandez MJ, Raichle ME, Stone HL: The role of the sympathetic nervous system in cerebral blood flow autoregulation. Eur Neurol 6: 175-179, 1971/72

11) Høedt-Rasmussen K, Skinhøj E: Transneural depression of the cerebral hemispheric metabolism in man. Acta Neurol Scand 40: 41-46, 1964

12) Høedt-Rasmussen K, Skinhøj E, Paulson O, Ewald J, Bjerrum JK, Fahrenkrug A, Lassen NA: Regional cerebral blood flow in acute apoplexy. The "luxury perfusion syndrome" of brain tissue. Arch Neurol (Chicago) 17:271-281, 1967

13) Jones SC, Fedora T, Lear J, Greenberg JH, Reivich $\mathrm{M}$ : The flow-metabolism couple in normal rat brain. $J$ Cereb Blood Flow Metabol 1 [Suppl] 1: 488-489, 1981

14) Kanno I, Lassen NA: Two methods for calculating regional cerebral blood flow from emission computed tomography of inert gas concentrations. $J$ Comput Assist Tomogr 3: 71-76, 1979

15) Kawase $T$, Mizukami M, Araki G, Nagata K: Critical flow levels in cerebral ischemia. I. Occlusive cerebrovascular disease. No To Shinkei 32: 1247-1255, 1980 (in Japanese)

16) Kety SS: Circulation and metabolism of the human brain in health and disease. Amer $J$ Med 8: 205-217, 1950

17) Kuhl DE, Phelps ME, Kowell AP, Metter EJ, Selin C, Winter J: Effects of stroke on local cerebral metabolism and perfusion: Mapping by emission computed tomography of ${ }^{18} \mathrm{FDG}$ and ${ }^{13} \mathrm{NH}_{3}$. Ann Neurol 8: 47-60, 1980

18) Lassen NA: The luxury-perfusion syndrome and its possible relation to acute metabolic acidosis localized within the brain. Lancet 2: 1113-1115, 1966

19) Lassen NA: Incomplete cerebral infarction. Focal incomplete ischemic tissue necrosis not leading to emollision. Stroke 13: 522-523, 1982

20) Lassen NA, Christensen MS: Physiology of cerebral blood flow. $B r J$ Anaesth 48: 719-734, 1976

21) Lassen NA, Henriksen L, Paulson O: Regional cerebral blood flow in stroke by ${ }^{133}$ xenon inhalation and emission tomography. Stroke 12: 284-288, 1981

22) Lenzi GL, Frackowiak RSJ, Jones T: Cerebral oxygen metabolism and blood flow in human cerebral ischemic infarction. J Cereb Blood Flow Metabol 2: 321-335, 1982

23) Meyer JS, Naritomi H, Sakai F, Ishihara N, Grant P: Regional cerebral blood flow, diaschisis, and steal after stroke. Neurol Res 1: 101-119, 1979

24) Meyer JS, Shinohara Y, Kanda T, Fukuuchi Y, Ericsson AD, Kok NK: Diaschisis resulting from acute unilateral cerebral infarction. Quantitative evidence for man. Arch Neurol 23: 241-247, 1970

25) Ogawa A, Seki H, Yoshimoto T, Suzuki J: Experimental focal cerebral infarction. Part 2. Hemodynamics in and around the focal cerebral infarction following recirculation. Jpn J Stroke 4: 10-17, 1982 
(in Japanese)

26) Olsen TS, Larsen B, Herning M, Skriver EB, Lassen NA: Blood flow and vascular reactivity in collaterally perfused brain tissue. Evidence of an ischemic penumbra in patients with acute stroke. Stroke 14: 332-341, 1983

27) Olsen TS, Larsen B, Skriver EB, Herning $M$, Enevoldsen E, Lassen NA: Focal cerebral hyperemia in acute stroke. Incidence, pathophysiology and clinical significance. Stroke 12: 598-607, 1981

28) Paulson OB: Regional cerebral blood flow in apoplexy due to occlusion of the middle cerebral artery. Neurology (Minneap) 20: 63-77, 1970

29) Paulson OB, Lassen NA, Skinhøj E: Regional cerebral blood flow in apoplexy without arterial occlusion. Neurology (Minneap) 20:125-138, 1970

30) Raichle ME, Grubb RLJ, Gado MH, Eichling JO, Ter-Pogossian MM: Correlation between regional cerebral blood flow and oxidative metabolism. In vivo studies in man. Arch Neurol 33: 523-526, 1976

31) Rosner G, Heiss WD: Survival of cortical neurons as a function of residual flow and duration of ischemia. $J$ Cereb Blood Flow Metabol 3 [Suppl] 1: 393-394, 1983

32) Sakakibara T: Experimental studies on the mechanism of acute brain swelling. Neuronal factors controlling cerebral vascular tonicity. Neurol Med Chir (Tokyo) 20: 363-372, 1980 (in Japanese)

33) Sercombe R, Aubineau P, Edvinsson L, Mamo $H$, Owman $\mathrm{CH}$, Pinard E, Seylaz J: Neurogenic influence on local cerebral blood flow. Effect of catecholamines or sympathetic stimulation as correlated with the sympathetic innervation. Neurology (Minneap) 25: 954-963, 1975

34) Shalit MN, Reinmuth OM, Shimojyo S, Scheinberg P: Carbon dioxide and cerebral circulatory control. III. The effects of brain stem lesions. Arch Neurol (Chicago) 17: 342-353, 1967

35) Slater R, Reivich M, Goldberg H, Banka R, Greenberg J: Diaschisis with cerebral infarction. Stroke 8: $684-690,1977$

36) Sokoloff L: Relation between physiological function and energy metabolism in the central nervous system. J Neurochem 29: 13-26, 1977

37) Stokely EM, Sveinsdottir E, Lassen NA, Rommer P: A single photon dynamic computer assisted tomo- graph (DCAT) for imaging brain function in multiple cross sections. J Comput Assist Tomogr 4: 230240,1980

38) Sugiyama H: Cerebral blood flow in patients with hypertensive intracerebral hemorrhage. With regard to differences in the mechanism of flow reduction between putaminal and thalamic hemorrhages. Neurol Med Chir (Tokyo) 24: 564-572, 1984 (in Japanese)

39) Symon L, Held K, Dorsch NWC: On the myogenic nature of the autoregulatory mechanism in the cerebral circulation. Eur Neurol 6: 11-18, 1971/72

40) Tamura A, Asano T, Sano K: Correlation between rCBF and histological changes following temporary middle cerebral artery occlusion. Stroke 11: 487-493, 1980

41) Tsukahara N: Synaptic plasticity in the mammalian central nervous system. Annu Rev Neurosci 4: 351379,1981

42) Uemura L, Goto K, Ishii K, Ito Z, Hen R, Kawakami $H$ : Sequential changes of regional cerebral circulation in cerebral infarction. Neuroradiology 16: 228232,1978

43) von Monakow C: Die Lokalisation im Grosshirn und der Abbau der Funktion durch kortikale Herde. Wiesbaden, JF Bergmann, 1914, pp 26-34

44) Wise RJS, Bernardi S, Frackowiak RSJ, Legg NJ, Jones $\mathrm{T}$ : Serial observations on the pathophysiology of acute stroke. The transition from ischemia to infarction as reflected in regional oxygen extraction. Brain 106: 197-222, 1983

45) Wise R, Rhodes C, Gibbs J, Frackowiak R, Jones T: The relationship between oxygen metabolism and glucose utilization in early cerebral infarcts. $J$ Cereb Blood Flow Metabol 3 [Suppl] 1: 580-581, 1983

46) Wood JH, Polyzoidis KS, Epstein CM, Gibby GL, Tindall GT: Improvement in cerebral blood flow and power spectral EEG after isovolemic hemodilution in stroke patients. J Cereb Blood Flow Metabol 3 [Suppl] 1: 588-589, 1983

Address reprint requests to: H. Sugiyama, M.D., Department of Neurosurgery, Iwate Medical University, 191 Uchimaru, Morioka 020, Japan. 